\title{
Prospective Associations Between Fixed-Term Contract Positions and Mental Illness Rates in Denmark's General Workforce: Protocol for a Cohort Study
}

Harald Hannerz ${ }^{1}$, PhLic; Hermann Burr ${ }^{2}$, PhD; Helle Soll-Johanning ${ }^{1}$, PhD; Martin Lindhardt Nielsen ${ }^{3}$, PhD; Anne Helene Garde ${ }^{1}$, PhD; Mari-Ann Flyvholm ${ }^{1}$, PhD

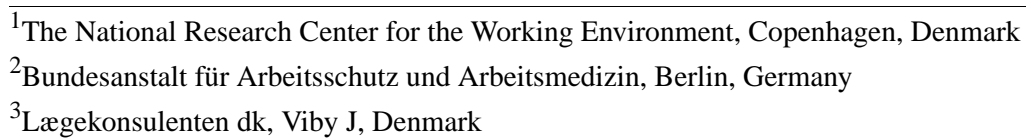

\section{Corresponding Author:}

Harald Hannerz, PhLic

The National Research Center for the Working Environment

Lersø Parkallé 105

Copenhagen, 2100

Denmark

Phone: 4539165460 ext 39165460

Email: hha@nrcwe.dk

\begin{abstract}
Background: In 2018, 14\% of employees in the European Union had fixed-term contracts. Fixed-term contract positions are often less secure than permanent contract positions. Perceived job insecurity has been associated with increased rates of mental ill health. However, the association between fixed-term contract positions and mental ill health is uncertain. A recent review concluded that the quality of most existing studies is low and that the results of the few studies with high quality are contradictory.

Objective: This study aims to estimate the incidence rate ratios (RRs) of psychotropic drug use and psychiatric hospital treatment. These ratios will be considered, first, in relation to the contrast fixed-term versus permanent contract and, second, to fixed-term contract versus unemployment.

Methods: Interview data with baseline information on employment status from the Danish Labor Force Surveys in the years 2001-2013 will be linked to data from national registers. Participants will be followed up for up to 5 years after the interview. Poisson regression will be used to estimate incidence RRs for psychiatric hospital treatment for mood, anxiety, or stress-related disorders and redeemed prescriptions for psychotropic drugs, as a function of employment status at baseline. The following contrasts will be considered: full-time temporary employment versus full-time permanent employment and temporary employment (regardless of weekly working hours) versus unemployment. The analyses will be controlled for a series of possible confounders. People who have received sickness benefits, have received social security cash benefits, have redeemed a prescription for psychotropic drugs, or have received psychiatric hospital treatment for a mental disorder sometime during a 1-year period preceding baseline will be excluded from the study. The study will include approximately 134,000 participants (13,000 unemployed, 106,000 with permanent contracts, and 15,000 with fixed-term contracts). We expect to find approximately 16,400 incident cases of redeemed prescriptions of psychotropic drugs and 2150 incident cases of psychiatric hospital treatment for mood, anxiety, or stress-related disorders.
\end{abstract}

Results: We expect the analyses to be completed by the end of 2021 and the results to be published in mid-2022.

Conclusions: The statistical power of the study will be large enough to test the hypothesis of a prospective association between fixed-term contract positions and mental illness in the general workforce of Denmark.

International Registered Report Identifier (IRRID): DERR1-10.2196/24392

(JMIR Res Protoc 2021;10(2):e24392) doi: 10.2196/24392

\section{KEYWORDS}

cohort study; fixed-term employment; fixed term contract; unemployment; psychotropic drugs; psychiatric hospital treatment 


\section{Introduction}

\section{Background}

Mental health problems are the most frequent single cause of disability benefits in the Organization for Economic Co-operation and Development (OECD) [1]. In Denmark, mental health problems account for almost half of all new applications for disability benefits [1].

The prevalence of temporary employment contracts in the European Union (EU) has been quite stable since 2005 [2]. Approximately $14 \%$ of employees (27 million persons) in the EU had a fixed-term contract in 2018 [3]. The total cost of mental health illness in the EU-28 nations was estimated to be approximately 600 billion euros in 2015, which corresponds to $4.1 \%$ combined gross domestic product of the 28 nations [4]. It has been hypothesized that some cases of mental health illness may be due to insecure employment contracts [5]. The main reason for suspecting a link between fixed-term contracts and mental health problems is that perceived job insecurity has been associated with an increased prevalence of depression, anxiety, emotional exhaustion, life satisfaction, and psychological well-being [6] as well as an increased risk of developing depressive symptoms [7]. In addition, employees in fixed-term contracts often have less influence on workplace decisions than employees with permanent contracts [8,9]. Furthermore, a low decision latitude has been associated with an increased risk of developing clinical depression [10].

However, it is still not clear whether fixed-term contracts pose a risk for poor mental health. A review by Hünefeld and Köper [5] considered 84 estimated associations between fixed-term versus permanent contract and mental health. Statistical significance was reported in $40 \%$ of the included studies, but only half of the significant associations were positive. Moreover, a recent systematic review and meta-analysis of studies on fixed-term versus permanent contracts and mental health problems concluded (1) that the quality of most existing studies was low and (2) that the results of the few studies with sufficient quality were contradictory [11].

The association between unemployment and mental health disorders has been robustly researched and published. There is a consensus that people who are unemployed are at increased risk of developing mental health problems and that employees with mental health problems are at increased risk of becoming unemployed [12]. A substantial reason for the association between unemployment and mental illness is attributed to the mental distress of chronic financial insecurity [7]. From this perspective, it has been hypothesized that the anticipation of a job loss can be detrimental to mental health as unemployment itself [7]. Recently, a meta-analysis was carried out to estimate the relative risk of developing depression as a function of unemployment and self-perceived job insecurity [7]. The study included results from 20 cohort studies, of which 14 compared the risk among unemployed with the risk among employees, whereas 6 compared the risk among employees with perceived job insecurity with that among other employees. The odds ratio for the contrast unemployment versus employment was estimated to be 1.19 (95\% CI 1.11-1.28), whereas the odds ratio for "secure versus unsecure employment" was estimated to be 1.29 (95\% CI 1.06-1.57).

\section{Objectives}

This project aims to estimate the incidence rate ratios (RRs) of psychotropic drug usage and psychiatric hospital treatment. These ratios will be considered in relation to the contrast "fixed-term versus permanent contract" and to "fixed-term contract (regardless of weekly working hours) versus unemployment" among the general population of Denmark. The second analysis will be performed to elucidate the hypothesis of Kim and von dem Knesebeck [7], which states that the anticipation of a possible job loss can be as detrimental for the mental health as unemployment itself.

People may work part time due to health issues or because they are not able to find a full-time job. They may also have chosen to work part time, for example, for furthering their education, caring for a parent or child, or engaging in hobbies or sports activities. The reason for excluding part-time workers in the first analysis is that a participant may have chosen to work part time due to ill health. The reason for not excluding part-time workers in the second analysis is that our data do not permit differentiation between part-time and full-time unemployment.

Job insecurity and unemployment have been associated with an increased risk of mental distress from chronic financial insecurity, which in turn has been associated with an increased risk of mental illness [13-15]. It is reasonable to believe that most people are financially more secure in a fixed-term contract position than they are in a state of unemployment. From this viewpoint, we expect the risk of developing mental health illnesses to be higher among unemployed people than among employees with a fixed-term contract. Likewise, we expect the risk to be higher among employees with a fixed-term contract than among employees with a permanent contract.

\section{Methods}

\section{Ethics Approval}

The study will comply with The Act on Processing of Personal Data, Denmark (Act No. 429 of May 31, 2000), which implements the European Union Directive 95/46/EC on the protection of individuals. The data usage was approved by the Danish Data Protection Agency (file number 2001-54-0180). The ethical and legal aspects of the project were approved by Statistics Denmark, accounting for 704291. In Denmark, register studies, which do not include medical procedures, are not part of the ethical committee system.

\section{Data Sources}

All residents of Denmark have access to tax-financed health care. The educational system is generally tax financed. The so-called flexicurity model provides an income safety net for the unemployed, with unemployment insurance benefits for members of unemployment insurance funds. The residents of Denmark are also entitled to maternity and paternity benefits, sickness-absence benefits, disability benefits, and if needed, social security cash benefits. Person-based data on health care services and redeemed prescriptions of medicine and welfare 
benefits payments are collected and reported in national registers, with unique personal identification numbers, which are assigned to all residents of Denmark [16].

This study will be based on baseline data on employment status from the Danish Labor Force Survey (DLFS) 2001-2013 and follow-up data on health from a series of registers, which cover the entire population of Denmark. The following registers will be used: the Central Person Register (CPR) [17], the Employment Classification Module (ECM) [18], the Danish Education Registers [19], the Danish Family Income Register [20], the Danish Register for Evaluation of Marginalization (DREAM) [21], the Psychiatric Central Research Register [22], and the National Prescription Register [23]. Linkage will be based on participants' personal identification numbers. The data sources and information to be included are listed in Table 1.

Table 1. The data sources of the project.

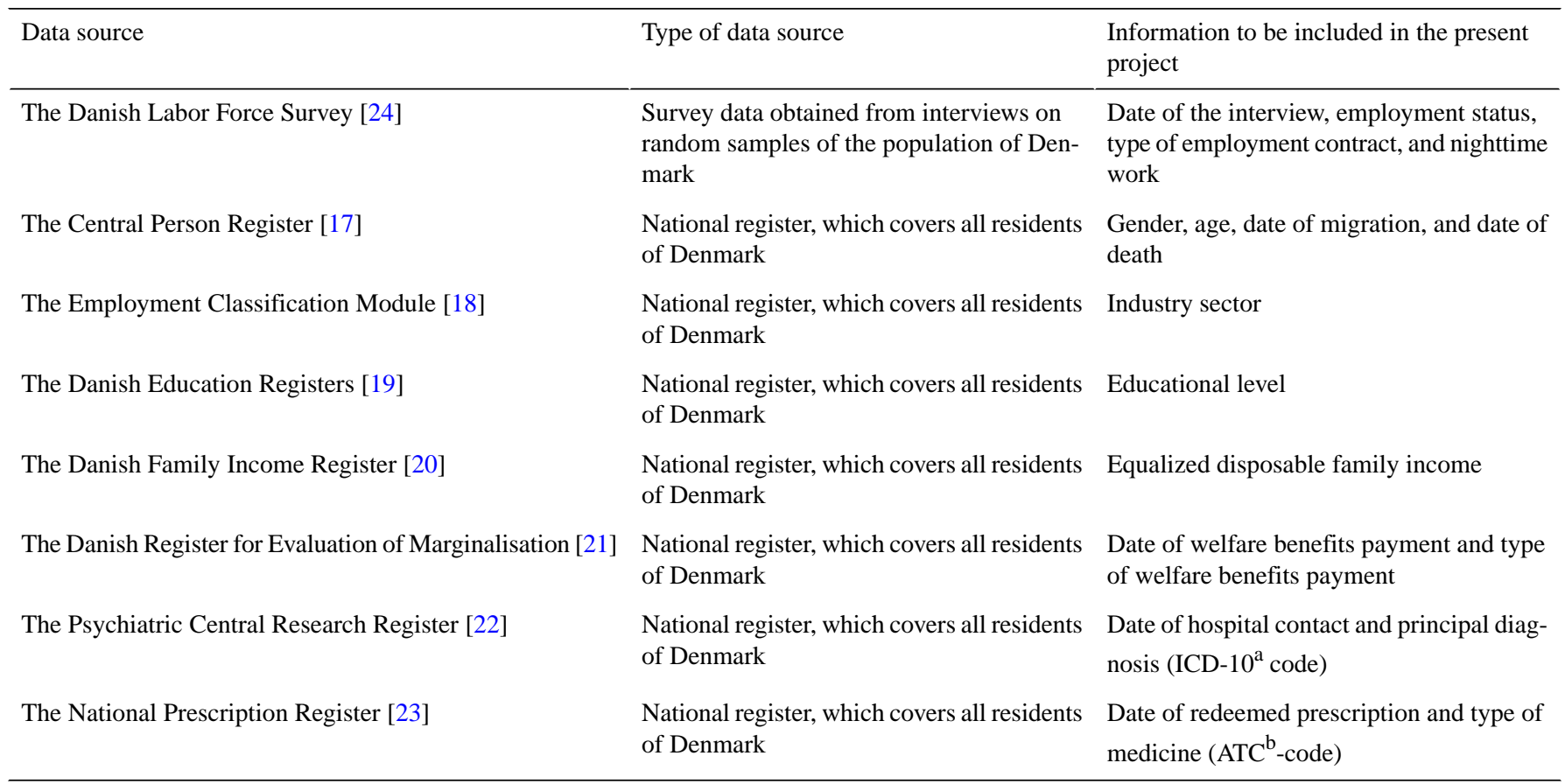

aCD-10: International Statistical Classification of Diseases and Related Health Problems, 10th Revision.

bATC: Anatomical Therapeutic Chemical Classification System.

DLFS is based on quarterly random samples of 15- to 74-year-old residents of Denmark, with systematic oversampling of unemployed people. Each participant is invited to be interviewed 4 times over the course of a year and a half. The purpose of the interviews is to collect person-based information on inter alia, labor market attachment, type of contract, and working hours [24]. Among those invited for the DFLS, the response rate decreased over time from $70 \%$ in 2002 to $53 \%$ in 2013 [25]. The CPR contains, inter alia, information on gender, addresses, and dates of birth, death, and migrations for every person who is or has been a resident of Denmark sometime between 1968 and the present time. The ECM contains annual, person-based information on, inter alia, the socio-economic status, occupation, and industry of the residents of Denmark. The Danish Education Registers contain person-based information on, inter alia, a person's highest educational attainment. The Danish Family Income Register contains information on household income. DREAM contains weekly, person-based information on social transfer payments (welfare benefits payments) such as maternity and paternity benefits, sickness-absence benefits, unemployment benefits, social security cash benefits, and state educational grants. DREAM has existed since 1991 and covers all residents of Denmark. The weekly benefits data are recorded if the person has been on a benefit for 1 or more days of the week. However, as only 1 type of social transfer payment can be registered per week, types of benefits are prioritized in the case of data overlap. The above-mentioned social transfer payments are prioritized in the order listed, that is, maternity and paternity benefits have higher priority than sickness-absence benefits, which in turn have higher priority than unemployment benefits, etc. The Psychiatric Central Research Register contains person-based information on inpatients, outpatients, and emergency ward visits in all psychiatric hospital departments in Denmark. The National Prescription Register contains person-based data on all redeemed prescriptions at pharmacies in Denmark.

This study has access to the data on Anatomical Therapeutic Chemical Classification System (ATC) codes [26] from the National Prescription Register for the time period 2000-2014 and International Statistical Classification of Diseases and Related Health Problems, 10th Revision (ICD-10) codes [27] from the Psychiatric Central Research Register for the time period 1995-2017.

\section{Clinical Endpoints}

RRs will be examined for the following endpoints:

- Redeemed prescriptions for any type of psychotropic medicine, that is, drugs in the ATC-code category N05 (psycholeptica) or N06 (psychoanaleptica) 
- Psychiatric hospital treatment with mood, anxiety, or stress-related disorder (ICD-10: F30-F41 or F43) as the principal diagnosis

The following mental disorders are included in the above case definition:

- F30 Manic episode

- F31 Bipolar affective disorder

- F32 Depressive episode

- F33 Recurrent depressive disorder

- F34 Persistent mood (affective) disorders

- F38 Other mood (affective) disorders

- F39 Unspecified mood (affective) disorder

- F40 Phobic anxiety disorders

- F41 Other anxiety disorders

- F43 Reaction to severe stress and adjustment disorders

\section{Exposure}

The following exposure categories will be considered: unemployed but actively searching for a job and ready to start working within 14 days, employed on a fixed-term contract position, and employed on a permanent contract. The categories are based on the DLFS-questionnaire [18].

\section{Covariates}

The literature suggests that estimated risks of mental health depend on gender [28,29], age [30-32], calendar year [33], education level [34], and income [35-38]. Moreover, it has been shown that the birth of a child may result in maternal [39] and paternal [40] postpartum depression.

The following covariates will therefore be regarded in all analyses: gender, age, calendar time of the interview, education level (at the end of the calendar year preceding the interview), equivalent disposable family income (in the calendar year preceding the interview), and maternity or paternity benefits (in the 1-year period preceding the interview).

In addition to the above, the following covariates will be regarded in the analyses of differences between employees with fixed-term and permanent contracts: main industry (in the calendar year preceding the interview), unemployment benefits (in the 1-year period preceding the interview), state educational grants (in the 1-year period preceding the interview), and nighttime work (at the time of the interview). We control for industry, as a previous study has found significant industry-related inequalities in the rate of mood disorders among employees in the general working population of Denmark [41]. We control for unemployment benefits and state educational grants in the 1-year period preceding the interview, as we believe that people's attitudes toward fixed-term and permanent contracts may depend on their previous labor market attachment. We control for nighttime work because it has been shown that the prevalence of psychotropic drug usage in Denmark is greater among shift workers than among workers without shift work [42].

The variables will be operationalized as follows:

\section{Gender}

Gender is classified into male or female as registered in the CPR.

\section{Age}

In this study, we will not have access to the exact dates of birth, but we will have access to information about the birth year of the participants, that is, we will know what their integer age was at the very beginning and at the very end of a calendar year. To form baseline age categories, the participants who were interviewed before July 1 in a given calendar year will be assigned the integer age they had at the beginning of that year, whereas the participants who were interviewed after June 30 will be assigned the integer age they would have at the end of the calendar year. The participants will thereafter be divided into 10-year age groups $(20-29, \ldots 50-59$ years), and the age group will be treated as a categorical variable.

\section{Calendar Time of the Interview}

The calendar years of the interviews will be treated as a categorical variable and divided into the following categories: 2001-2003, 2004-2006, 2007-2009, and 2010-2013.

\section{Educational Level (at the End of the Calendar Year Preceding the Interview)}

A person's highest attained education is registered and classified with a 2-digit code in the Danish Education Registers [19]. In this study, it will be divided as follows (Table 2) into the categories low, medium, high, and unstated.

Table 2. Classification of education levels.

\begin{tabular}{|c|c|}
\hline The present project & The Danish Education Registers \\
\hline Low & - 10 Primary and lower secondary education \\
\hline High & $\begin{array}{l}\text { - } \quad 50 \text { Medium-term tertiary education } \\
\text { - } \quad 60 \text { Bachelor's degree } \\
\text { - } \quad 70 \text { Master's degree or equivalent tertiary education level } \\
\text { - } \quad 80 \text { Doctoral degree or equivalent tertiary education level }\end{array}$ \\
\hline Unstated & - Unstated \\
\hline
\end{tabular}




\section{Equivalized Disposable Family Income (in the Calendar Year Preceding the Interview)}

The equivalent disposable income is the total income of a household, after tax and other deductions, which is available for spending or saving, divided by the number of household members converted into equalized adults; household members are equalized or made equivalent by weighting each according to their age, using the so-called modified OECD equivalence scale (cited from Eurostat [43]).

The equivalent disposable income is calculated in 3 steps (cited from Eurostat [43]):

- All monetary incomes received from any source by each member of a household are added up. These include income from work, investment, and social benefits, as well as any other household income; taxes and social contributions that have been paid are deducted from this sum.

- To reflect differences in household size and composition, the total (net) household income is divided by the number of 'equivalent adults,' using a standard (equivalence) scale: the modified OECD scale. This scale gives a weight to all members of the household (and then adds these up to arrive at the equivalized household size): 1.0 to the first adult, 0.5 to the second and each subsequent person aged 14 and over, and 0.3 to each child aged under 14 .

- Finally, the resulting figure is called the equivalent disposable income and is attributed equally to each member of the household.

This study will treat the equivalent disposable family income as a categorical variable, divided into low, medium, and high in accordance with calendar-year specific sample tertiles. The tertiles will be based on all DLFS responders who were 20 to 59 years old and employed at the time of the interview.

\section{Main Industry (in the Calendar Year Preceding the Interview)}

The industries will be divided into 10 groups, as shown in Table 3 . The industrial codes are based on the industrial classification DB93 [44] in 1999-2002, DB03 [45] in 2002-2007, and DB07 [46] in the calendar years 2008-2013.

Table 3. Industrial groups coded according to the classifications DB93, DB03, and DB07, respectively.

\begin{tabular}{|c|c|c|c|}
\hline \multirow[t]{2}{*}{ Industrial group } & \multicolumn{3}{|l|}{ Code according to } \\
\hline & DB93 & DB03 & DB07 \\
\hline Agriculture, forestry, hunting, and fishing & $\mathrm{A}+\mathrm{B}$ & $\mathrm{A}+\mathrm{B}$ & A \\
\hline Manufacturing, mining, and quarrying & $\mathrm{C}+\mathrm{D}$ & $\mathrm{C}+\mathrm{D}$ & $\mathrm{B}+\mathrm{C}$ \\
\hline Construction & $\mathrm{F}$ & $\mathrm{F}$ & $\mathrm{F}$ \\
\hline Wholesale and retail trade and repair of motor vehicles and motorcycles & $\mathrm{G}$ & G & G \\
\hline Transporting and storage & I & I & $\mathrm{H}$ \\
\hline Accommodation and food service activities & $\mathrm{H}$ & $\mathrm{H}$ & I \\
\hline Human health and social work activities & $\mathrm{N}$ & $\mathrm{N}$ & Q \\
\hline Other & $\mathrm{E}, \mathrm{J}, \mathrm{K}, \mathrm{L}, \mathrm{M}, \mathrm{O}, \mathrm{P}, \mathrm{Q}$ & E, J, K, L, M, O, P, Q & $\begin{array}{l}\mathrm{D}, \mathrm{E}, \mathrm{J}, \mathrm{K}, \mathrm{L}, \mathrm{M}, \mathrm{N}, \\
\mathrm{O}, \mathrm{P}, \mathrm{R}, \mathrm{S}, \mathrm{T}, \mathrm{U}\end{array}$ \\
\hline Unstated & $\mathrm{X}$ & Missing & Missing \\
\hline
\end{tabular}

\section{Unemployment Benefits (in the One-Year Period Preceding the Interview)}

This variable is equal to 1 if the participant, according to DREAM, received unemployment benefits (DREAM codes: 111-115, 121-126, 211-219, 231, 232, and 299) at least once during the 1 -year period preceding the DLFS interview. Otherwise, it is equal to 0 .

\section{Maternity or Paternity Benefits (in the One-Yar Period Preceding the Interview)}

This variable is equal to 1 if the participant, according to DREAM, received maternity or paternity benefits (DREAM code: 881 ) at least once during the 1-year period preceding the DLFS interview. Otherwise, it is equal to 0.

\section{State Educational Grants (in the One-Year Period Preceding the Interview)}

This variable is equal to 1 if the participant, according to DREAM, received state educational grant payments (DREAM codes: 651, 652, and 661) at least once during the 1-year period preceding the DLFS interview. Otherwise, it is equal to 0.

\section{Nighttime Work}

In the DLFS interview, the participants were asked whether they worked at night during the last 4 weeks. In this study, nighttime work will be treated as a categorical variable in accordance with the 3 response categories Yes, regularly, Yes, occasionally, and No.

\section{Follow-Up}

The study will be based on data that already exist. The included participants of the DLFS will be followed by national registers. The follow-up in the register data will start on the date when 6 weeks would have passed since the first DLFS interview and end on the date when any of the following events occur: 5 years pass since the date of the start of the follow-up, the participant emigrates, the participant dies, the participant meets the clinical endpoint of the analysis, or the study period ends. The end of the study period was set at the end of the calendar years 2014 
and 2017 for redeemed prescriptions of psychotropic drugs and psychiatric hospital treatments, respectively. Person-years at risk will be calculated for each of the included participants. Participants who die or emigrate during the follow-up will be censored at the time of the event. That is, they will participate with person-years at risk until the time of death or emigration.

\section{Inclusion Criteria}

The primary analyses will be based on data from the participants' first interview in the time period 2001-2013. In the comparisons between employees with a full-time fixed-term versus a full-time permanent contract, we will require inclusion criteria 1-6 fulfilled (see below). In the comparisons between employees with a fixed-term contract (regardless of weekly working hours) versus unemployed people, we will require that criteria 1-4 and criteria 7 are fulfilled.

Inclusion criteria:

1. The participants were aged between 20 and 59 years at the time of the interview.

2. They did not receive any social transfer payments other than holiday allowance (DREAM code: 121), unemployment benefits (DREAM codes: 111-115, 122-126, 211-219, 231, 232, 299), maternity or paternity benefits (DREAM code: 881 ), or state educational grants (DREAM codes: $651,652,661)$ during the one-year period preceding the interview.

3. They did not receive any psychiatric hospital treatment with mental disorders (ICD-10: F01-F99) as the principal diagnosis during a 1-year period preceding the start of follow-up.

4. They did not redeem any prescription for psychotropic drugs (ATC: N05-N06) during a 1-year period preceding the start of follow-up.

5. They were employees, according to the interview.

6. They usually worked $\geq 32 \mathrm{~h}$ a week, according to the interview.

7. They were either unemployed but actively searching for a job and ready to start working within 14 days or employed with a fixed-term contract at the time of the interview.

Moreover, it is necessary that the concerned DLFS-based exposure variables and covariates are nonmissing.

\section{Primary Statistical Analysis}

Poisson regression will be used to estimate incidence RRs for psychiatric hospital treatment for mood, anxiety, or stress-related disorders and redeemed prescriptions for psychotropic drugs, as a function of employment status at baseline. The following contrasts will be considered: (1) Full-time fixed-term contract versus full-time permanent contract and (2) fixed-term contract (regardless of weekly working hours) versus unemployment. All analyses will be controlled for age, sex, disposable family income, educational level, calendar year of the interview, and reception of maternity or paternity benefits sometime during a 1-year period preceding baseline. The RRs for the contrast fixed-term versus permanent contract will, in addition to the above, be controlled for baseline industry group and nighttime work as well as reception of unemployment benefits and state study grants, sometime during a 1-year period preceding baseline. The logarithm of person-years at risk will be used as an offset. Likelihood ratio tests will be used to test first for main effects and then for effects of interaction with gender, age, and education level. We test for interactions, as it has been suggested that the strength of adverse health effects of fixed-term contracts depends on gender [47], age [48], and education level [49].

The main effects will be tested both for psychiatric hospital treatments and redeemed prescriptions for psychotropic drugs. The interaction effects will only be tested for redeemed prescriptions for psychotropic drugs. A Bonferroni correction will be used to adjust for multiple testing. We want the overall significance level to be less than or equal to 0.05 . Hence, each of the 10 tests will be conducted at a significance level of 0.005 . RRs for main effects will be estimated and presented with $99.5 \%$ CI. Moreover, the RRs for redeemed prescriptions for psychotropic drugs will be stratified (and presented with $99.5 \%$ CI) by gender, age, and educational level.

\section{Power Calculations}

Under the null hypothesis, we expected to find approximately 29 new cases of psychotropic drug usage and 3.4 new cases of psychiatric hospital treatment for mood, anxiety, or stress-related disorders per 1000 person-years at risk [50]. If we assume that approximately $15 \%$ of the otherwise eligible participants will be excluded due to exclusion criteria 1-4, the total number of expected cases in the concerned exposure categories will be approximately as shown in Table 4.

Table 4. The total number of expected cases in the concerned exposure categories.

\begin{tabular}{|c|c|c|c|}
\hline Exposure category & $\begin{array}{l}\text { Expected number of eligible } \\
\text { participants }\end{array}$ & $\begin{array}{l}\text { Expected number of psy- } \\
\text { chotropic drug cases }\end{array}$ & $\begin{array}{l}\text { Expected number of psychi- } \\
\text { atric hospital cases }\end{array}$ \\
\hline Fixed-term full-time contract & 10,600 & 1300 & 170 \\
\hline Permanent full-time contract & 106,000 & 13,000 & 1700 \\
\hline Fixed-term contract (regardless of weekly working hours) & 15,000 & 1800 & 240 \\
\hline Unemployment & 13,000 & 1600 & 210 \\
\hline
\end{tabular}

On the basis of the expected number of cases, the Poisson distribution, the Gauss propagation of error formulas, and the central limit theorem, we estimated the statistical power of the planned significance tests. The statistical powers for the main effects are given in Figures 1 and 2, for incident use of psychotropic drugs and psychiatric hospital treatment for mood, anxiety, or stress-related disorders, respectively, as a function of the underlying RR. 
Figure 1. Power to detect main effects of fixed-term contracts on the rates of new cases of psychotropic drug use, as a function of underlying rate ratios $(\alpha=.005)$.

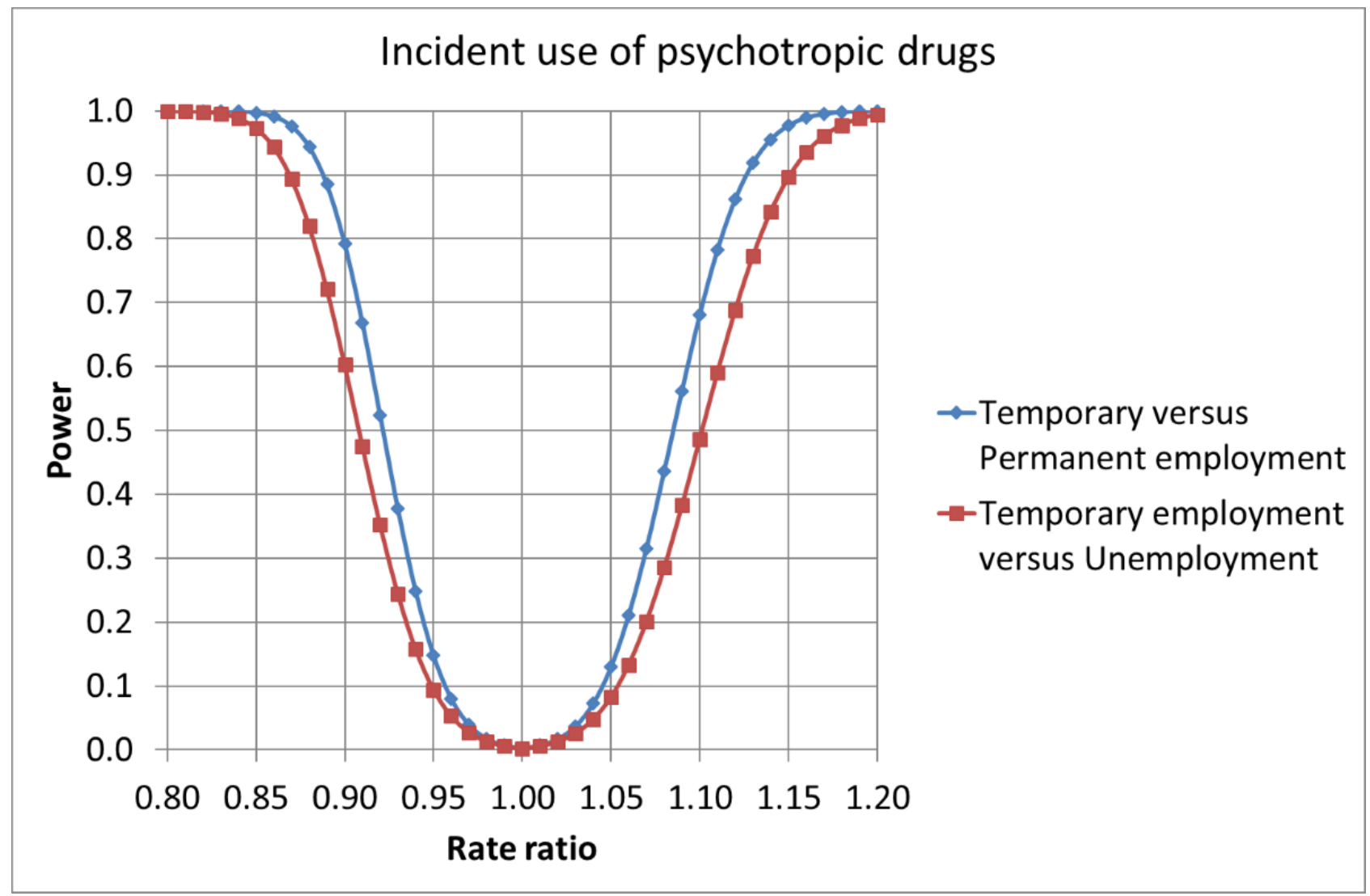

Figure 2. Power to detect main effects of fixed-term contracts on the rates of new cases of psychiatric hospital treatment for mood, anxiety, or stress-related disorders, as a function of underlying rate ratios $(\alpha=.005)$.

\section{Psychiatric hospital treatment for mood, anxiety or stress- related disorders}

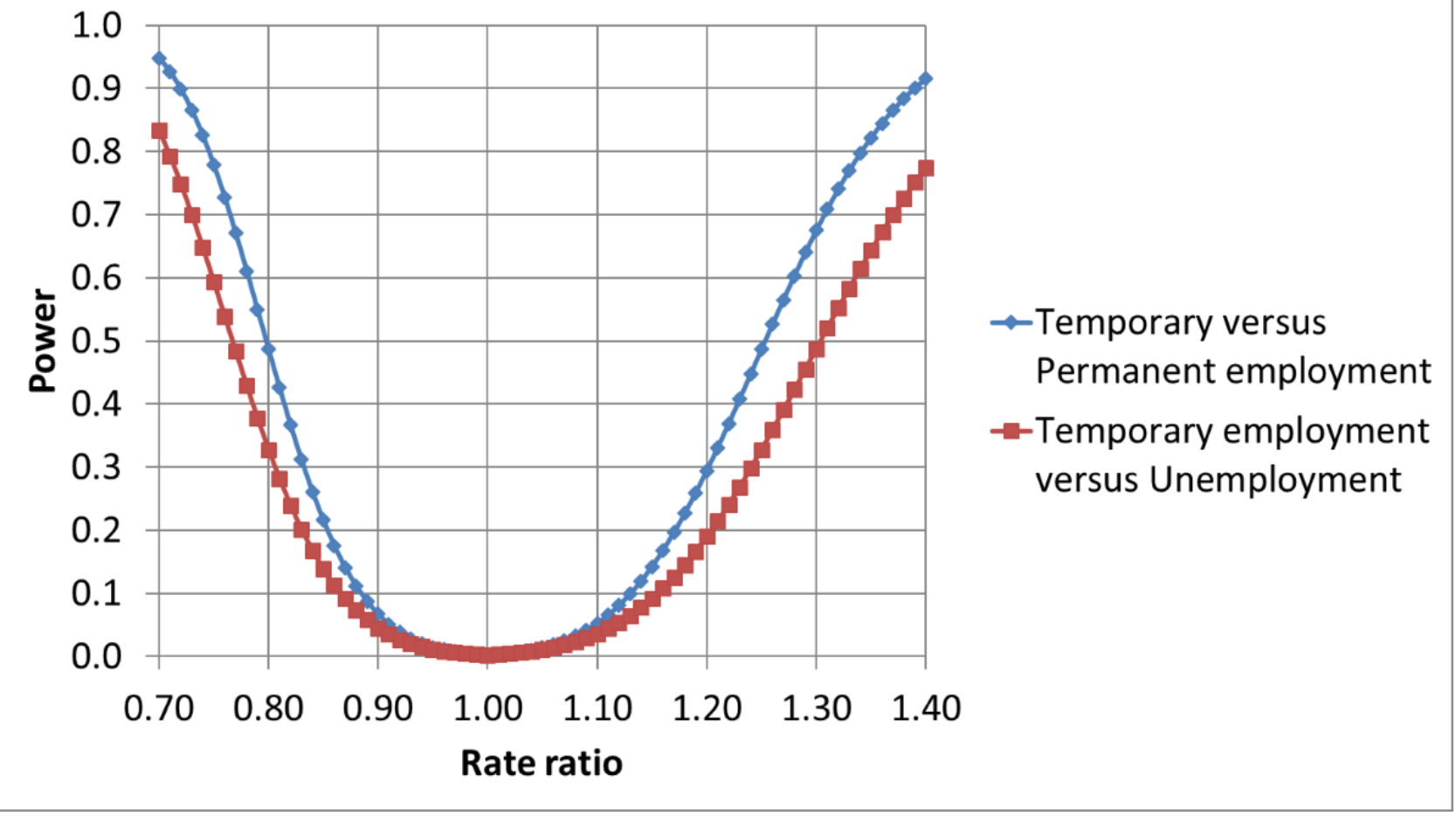


The statistical powers to detect interaction effects were estimated in relation to the Cohen $\mathrm{w}$ [51], where $\mathrm{w}=0.1$ is defined as a small effect, $\mathrm{w}=0.3$ is defined as a medium effect, and $\mathrm{w}=0.5$ is defined as a large effect. On the basis of the expected number of cases, test specific degrees of freedom, and the noncentral chi-square distribution, we estimated that the power to detect a small effect $(\mathrm{w}=0.1)$ is greater than 0.98 in each of the planned interaction tests of this project.

The calculations indicate that the power is sufficiently large to test both the main and interaction effects of fixed-term contracts on the incidence of psychotropic drug usage. The powers to detect effects of fixed-term contracts on the incidence of psychiatric hospital treatment for mood, anxiety, or stress-related disorders (Figure 2) are, however, quite low, and this needs to be taken into account when the results are evaluated.

\section{Sensitivity Analyses}

We will conduct 6 sensitivity analyses. The endpoint of the sensitivity analyses will be redeemed prescriptions of psychotropic drugs. Interaction effects will be disregarded. RRs will be estimated and presented with $99.5 \%$ CI. The RRs and their associated confidence intervals will not be regarded as statistical significance tests. However, they may strengthen, weaken, or invalidate the statistical conclusions of the primary analyses.

\section{Sensitivity Analysis 1: Exclusion of All Cases that Occurred Within 5 Years Preceding the Start of Follow-Up}

The primary analysis will exclude all people who received psychiatric hospital treatment or redeemed a prescription for psychotropic drugs sometime during a 1-year period before the start of the follow-up. Hence, no known current cases of psychiatric treatment will be included in the follow-up. It is, however, possible that people who received treatment more than 1 year before the follow-up will influence the analysis. To shed some light on this issue, we will conduct a sensitivity analysis in which we will exclude all people who received psychiatric hospital treatment or redeemed a prescription for psychotropic drugs sometime during a 5-year period before the start of the follow-up. This sensitivity analysis will be based on data from the participants' first interview in the period 2005-2013. Moreover, it will only include people who lived in Denmark throughout the concerned 5-year period. The statistical models and inclusion criteria will otherwise be the same as in the primary analysis. The interpretation of results will include the fact that approximately $20 \%$ of the population experiences mental health problems during their lifespan due to different causes; so the analysis may be overcontrolling.

\section{Sensitivity Analysis 2: Relapse Rate Ratios}

At this point, it is useful to further elucidate (/examine) the possible influence of former cases of psychiatric treatment on the association between fixed-term contract and psychotropic drug usage. To this end, we will estimate relapse RRs among the participants who were excluded from the first sensitivity analysis due to psychiatric hospital treatment or redeemed prescription for psychotropic drugs sometime between 1 and 5 years before the start of follow-up.
Current cases, that is, people who received treatment sometime during a 1-year period before the start of follow-up will still be excluded. The statistical models will otherwise be the same as in sensitivity analysis 1 .

\section{Sensitivity Analysis 3: Long-term Exposure Versus Exposure at a Single Time Point}

In the primary analysis, we regard the contrasts full-time fixed-term contract versus full-time permanent contract and fixed-term contract versus unemployment with the exposure categories defined at a single time point (the first interview). We want to know whether the strength of the concerned associations will increase if we base the exposure categories on more than one interview and only include people who belong to the same exposure category in all of their interview rounds. In other words, we want to know whether the strength of the associations will increase if we base the contrasts on long-term exposure instead of exposure at a single time point. To shed some light on this issue, we will conduct a sensitivity analysis in which we will only include people who (1) participated in more than one interview, (2) were aged between 20 and 59 years during their last interview, and (3) belonged to the same exposure category in all of their interview rounds. The follow-up of the included participants will commence 6 weeks after their last interview. The statistical models and inclusion criteria will otherwise be the same as in the primary analysis.

\section{Sensitivity Analysis 4: Minimally Adjusted Rate Ratios}

In the primary analyses, we will exclude all people who received sickness benefits or social security cash benefits during a 1-year period before the baseline interview. Moreover, we control for disposable family income as well as a series of other covariates. It is possible that the rigorous inclusion criteria and the many control variables will lead to overly conservative estimates. Therefore, we will conduct a sensitivity analysis in which we will (1) remove the second of the inclusion criteria listed in the method section and (2) remove all control variables except for gender, age, and education. The methods will otherwise be the same as in the primary analyses.

\section{Sensitivity Analysis 5: Reason for Being on a Fixed-Term Contract}

All EU-Labor Force Survey participants with a fixed-term contract are asked for the reason of having a fixed-term contract. Their answers are categorized as follows:

- It is a contract covering a period of training (apprentices, trainees, research assistants, etc)

- Person could not find a permanent job

- Person did not want a permanent job

- It is a contract for a probationary period

We want to know whether the risk of developing mental health illnesses among employees with a fixed-term contract depends on the reason for being on a fixed-term contract. To answer this question, we will estimate incidence RRs for redeemed prescriptions of psychotropic drugs as a function of the reason for being on a fixed-term contract.

Participants who did not want a permanent job (category 3) will serve as the reference group. We will include all employees on 
fixed-term contracts, who fulfilled inclusion criteria 1-5, as listed in the method section. The analyses will initially be conducted only with full-time employees ( $\geq 32 \mathrm{~h}$ a week) and then with all employees regardless of weekly working hours. The analyses will be controlled for all variables given in the Covariate section. The statistical model and follow-up periods will be the same as in the primary analysis.

\section{Sensitivity Analysis 6: Stratification by Industry Sector}

We know that the prevalence of fixed-term contracts in the Nordic countries depends on the industry sector [52], and that the rates of mood disorders in the general working population of Denmark depend on the industry sector [41]. It is possible that the effect of fixed-term contract positions on mental health illnesses also depends on the industry. Therefore, we conduct a sensitivity analysis in which we will stratify the results of the comparison between employees with a fixed-term and a permanent contract by the industry sector. The industries are grouped as shown in Table 3. The inclusion criteria and covariates will be the same as in the primary analysis.

Reasons why the association between fixed-term contracts and mental health illnesses might depend on industry could be, first, that chances for reemployment may depend on the industry sector and, second, that expectations regarding a fixed-term versus permanent contract may depend on the industry.

Another reason for stratifying by the industry sector is that the social partners might be interested in seeing the association between fixed-term contracts and mental health illnesses in their own industry sector.

\section{Possible Confounding From Smoking, Being Overweight, and Obesity: a Feasibility Study}

Studies have suggested that smoking habits $[53,54]$ and being overweight [55] predict depression. It has been estimated that the risk ratio of new-onset depression is 1.46 (95\% CI 1.03-2.07) for smokers versus nonsmokers [53], 1.08 (95\% CI 1.02-1.14) for overweight versus normal weight, and 1.57 (95\% CI 1.23-2.01) for obesity versus normal weight [55]. The DLFS does not contain any information about smoking habits and body weights of the participants. Therefore, we cannot control for these factors in the analyses. However, we have access to some collateral data, which we have used to estimate to what extent and in what direction the RRs of the present project are likely to be influenced by differences in distributions of body mass index and smoking habits. The collateral data were gathered from a survey on work and health in a random sample of the Danish population in 2005. The response rate of the survey was $62 \%$ [56]. In this study protocol, we have used the survey data to estimate the prevalence of smoking, being overweight, and obesity among 20-59-year-old people in Denmark, stratified by the exposure categories of interest to this study. The crude prevalence is given in Table 5, whereas prevalence that is standardized for age, gender, and education is given in Table 6 . The total sample of 20- to 59-year-old people was used as the standard population.

Table 5. Crude percentages of current smokers, people with moderate overweight ( $25 \leq \mathrm{BMI}<30$ ), and people with obesity (BMI $\geq 30)$, by exposure category, in a random sample of 20- to 59-year-old people in Denmark, 2005.

\begin{tabular}{llll}
\hline Exposure category & Current smoker, $\mathrm{n}(\%)$ & $25 \leq \mathrm{BMI}<30, \mathrm{n}(\%)$ & BMI $\geq 30, \mathrm{n}(\%)$ \\
\hline Fixed-term full-time contract $(\mathrm{n}=748)$ & $221(29.5)$ & $231(30.9)$ & $72(9.6)$ \\
Permanent full-time contract $(\mathrm{n}=8016)$ & $2438(30.4)$ & $2859(35.7)$ & $834(10.4)$ \\
$\begin{array}{l}\text { Fixed-term contract (regardless of weekly working hours; } \\
\mathrm{n}=908)\end{array}$ & $281(30.9)$ & $267(29.4)$ & $77(8.5)$ \\
Unemployment $(\mathrm{n}=393)$ & $141(35.9)$ & $123(31.3)$ & $54(13.7)$ \\
\hline
\end{tabular}

Table 6. Age (10-year classes), gender and education (low, medium, and high) standardized percentages of current smokers, people with moderate overweight $(25 \leq \mathrm{BMI}<30)$, and people with obesity $(\mathrm{BMI} \geq 30)$, by exposure category, in a random sample of 20 - to 59 -year-old people in Denmark, 2005 .

\begin{tabular}{|c|c|c|c|}
\hline Exposure category & $\begin{array}{l}\text { Current smoker, \% (95\% } \\
\text { CI) }\end{array}$ & $25 \leq \mathrm{BMI}<30, \%(95 \% \mathrm{CI})$ & $\mathrm{BMI} \geq 30, \%(95 \% \mathrm{CI})$ \\
\hline Fixed-term full-time contract & $31.8(28.4-35.6)$ & $33.0(29.6-36.8)$ & $10.6(8.5-13.3)$ \\
\hline Permanent full-time contract & $30.4(29.4-31.4)$ & $34.3(33.3-35.3)$ & $10.1(9.5-10.8)$ \\
\hline Fixed-term contract (regardless of weekly working hours) & $33.3(30.1-36.8)$ & $32.5(29.4-35.9)$ & $9.5(7.6-11.9)$ \\
\hline Unemployment & $36.5(32.1-41.4)$ & $31.9(27.4-37.1)$ & $14.1(11.0-18.2)$ \\
\hline
\end{tabular}

Table 6 suggests that the standardized prevalence among people with fixed-term full-time contracts are very similar to those among people with permanent full-time contracts. We note, however, that the estimated prevalence of smoking and obesity is greater among the unemployed than among the employees on fixed-term contracts. We want a rough estimate of the effect that such differences may have on the RR of mental health illnesses among employees on fixed-term contracts versus unemployed in our target population. Therefore, we have estimated the expected RR between these exposure categories under the assumption that the groups are equal in all respects other than smoking and BMI distribution and that an RR for depression can be used as a proxy for the RR of mental health illnesses. We used the following equation:

$$
E[R R]=\frac{1+p_{1}\left(R R_{1}-1\right)+p_{2}\left(R R_{2}-1\right)}{1+q_{1}\left(R R_{1}-1\right)+q_{2}\left(R R_{2}-1\right)} \times \frac{1+p_{3}\left(R R_{3}-1\right)}{1+q_{3}\left(R R_{3}-1\right)}
$$


where $R_{1}=1.08$ is the estimated rate ratio for depression among people in the category $25 \leq \mathrm{BMI}<30$ versus $\mathrm{BMI}<25, \mathrm{RR}_{2}=1.57$ is the estimated rate ratio for depression among people in the category $B M I \geq 30$ versus $B M I<25$, and $R_{3}=1.46$ is the estimated rate ratio for depression among smokers versus nonsmokers. The parameters $\mathrm{p}_{1}, \mathrm{p}_{2}$, and $\mathrm{p}_{3}$ are the standardized sample prevalences of overweight, obesity, and smoking, respectively, among people with fixed-term contracts (cf. Table 6). The parameters $\mathrm{q}_{1}, \mathrm{q}_{2}$, and $\mathrm{q}_{3}$ are the corresponding prevalence among the unemployed people (cf. Table 6).

The calculation yielded an estimated rate ratio of 0.96 . This means that a failure to control for overweight, obesity, and smoking in this project is expected to bias the estimated rate ratio for mental health illnesses among fixed-term versus unemployed people downward with a factor of 0.96 .

\section{Results}

We expect the analyses to be completed by the end of 2021 and the results to be published mid-2022.

\section{Discussion}

This study protocol contains a statistical analysis plan for a research project aimed at estimating prospective associations between fixed-term contracts and mental health illness in the general population of Denmark. As all covariates, outcome variables, inclusion criteria, statistical models, and significance levels are completely defined, published, and peer-reviewed before we link the exposure data of the project to its outcome data, we minimized the risk of hindsight bias.
A major strength of the project is that the data material is large enough to afford sufficient statistical power to detect important associations between fixed-term contracts and incident use of psychotropic medication. Another strength is that the outcome variables as well as the censoring variables (death and emigration) will be ascertained through national registers, which cover the entire population of Denmark. The study is weakened by the low response rate in the DLFS, which makes the representativeness of the participants questionable. Another weakness is the lack of data on lifestyle factors.

Studies have shown that the prevalence of depression tends to be higher among migrants than in the general population [57]. Studies of the general working population in Sweden [58] and Spain [59] have shown that immigrants are more likely to be on a fixed-term work contract. A survey of the general workforce in Canada found that newcomer immigrants (within the first 5 years) were on fixed-term contracts more often than natives [60]. Due to the comparability with Sweden and Canada, we expect the figures to be similar in Denmark. The response rate in questionnaire surveys among ethnic minorities in general is relatively low [61,62]; for example, half among non-Western immigrants compared with Danes [53]. The background to this study is the DLFS; thus, the issue of ethnicity cannot be addressed, as there are relatively few with immigrant background answering the survey.

Finally, it should be noted that the results of the study may not be fully transferable to other countries. Due to the relatively low employment protection in Denmark combined with a comprehensive income safety net for the unemployed, the so-called flexicurity model, it can be hypothesized that this may result in fewer fixed-term contracts in Denmark compared with other European countries [63].

\section{Acknowledgments}

The project is funded by the Danish Working Environment Research Fund, grant number 20195100796.

\section{Conflicts of Interest}

None declared.

\section{References}

1. Organisation for Economic Co-operation and Development. Sickness, Disability and Work: Breaking the Barriers. France: OECD Publishing; 2010.

2. Temporary and part-time jobs on the rise. European Union. URL: https://ec.europa.eu/eurostat/web/products-eurostat-news/ -/WDN-20180813-1 [accessed 2020-12-12]

3. Temporary employment. European Union. URL: https://ec.europa.eu/eurostat/web/products-eurostat-news/-/DDN-20190524-1 [accessed 2020-05-19]

4. OECD/EU. Health at a Glance Europe 2018: State of Health in the EU Cycle. Paris: OECD Publishing; 2018.

5. Hünefeldt L, Köper B. Fixed-term employment and job insecurity (JI) as risk factors for mental health. EJ Int Comp Labour Stud 2016;5(3):28 [FREE Full text]

6. Llosa J, Menéndez-Espina S, Agulló-Tomás E, Rodríguez-Suárez J. Job insecurity and mental health: a meta-analytical review of the consequences of precarious work in clinical disorders. Annals of Psychology 2018;34:211-223. [doi: $10.1037 / \mathrm{t} 68293-000]$

7. Kim TJ, von dem Knesebeck O. Perceived job insecurity, unemployment and depressive symptoms: a systematic review and meta-analysis of prospective observational studies. Int Arch Occup Environ Health 2016 May;89(4):561-573. [doi: 10.1007/s00420-015-1107-1] [Medline: 26715495] 
8. Aronsson G, Gustafsson K, Dallner M. Work environment and health in different types of temporary jobs. E J Work Organ Psychol 2002;11(2):151-175.

9. Parker SK, Griffin MA, Sprigg CA, Wall TD. Effect of temporary contracts on perceived work characteristics and job strain: a longitudinal study. Personnel Psychology 2002 Sep;55(3):689-719. [doi: 10.1111/j.1744-6570.2002.tb00126.x]

10. Madsen IEH, Nyberg ST, Magnusson Hanson LL, Ferrie JE, Ahola K, Alfredsson L, et al. Job strain as a risk factor for clinical depression: systematic review and meta-analysis with additional individual participant data. Psychol Med 2017 Jan 26;47(8):1342-1356. [doi: 10.1017/s003329171600355x] [Medline: 28122650]

11. Rönnblad T, Grönholm E, Jonsson J, Koranyi I, Orellana C, Kreshpaj B, et al. Precarious employment and mental health: a systematic review and meta-analysis of longitudinal studies. Scand J Work Environ Health 2019 Sep 01;45(5):429-443 [FREE Full text] [doi: 10.5271/sjweh.3797] [Medline: 31165899$]$

12. Paul KI, Moser K. Unemployment impairs mental health: meta-analyses. J Voc Behav 2009 Jun;74(3):264-282. [doi: 10.1016/j.jvb.2009.01.001]

13. Weich S, Lewis G. Poverty, unemployment, and common mental disorders: population based cohort study. Br Med J 1998 Jul 11;317(7151):115-119. [doi: 10.1136/bmj.317.7151.115] [Medline: 9657786]

14. Dunn N, Inskip H, Kendrick T, Oestmann A, Barnett J, Godfrey K, et al. Does perceived financial strain predict depression among young women? Longitudinal findings from the Southampton Women's Survey. Ment Health Fam Med 2008 Mar;5(1):15-21 [FREE Full text] [Medline: 22477842]

15. Sareen J, Afifi TO, McMillan KA, Asmundson GJ. Relationship between household income and mental disorders: findings from a population-based longitudinal study. Arch Gen Psychiatry 2011 Apr;68(4):419-427. [doi: 10.1001/archgenpsychiatry.2011.15] [Medline: 21464366]

16. Thygesen L, Ersbøll AK. Danish population-based registers for public health and health-related welfare research: introduction to the supplement. Scand J Public Health 2011 Jul;39(7 Suppl):8-10. [doi: 10.1177/1403494811409654] [Medline: 21775344]

17. Pedersen CB. The Danish civil registration system. Scand J Public Health 2011 Jul;39(7 Suppl):22-25. [doi: 10.1177/1403494810387965] [Medline: 21775345]

18. Petersson F, Baadsgaard M, Thygesen LC. Danish registers on personal labour market affiliation. Scand J Public Health 2011 Jul;39(7 Suppl):95-98. [doi: 10.1177/1403494811408483] [Medline: 21775363]

19. Jensen VM, Rasmussen AW. Danish education registers. Scand J Public Health 2011 Jul;39(7 Suppl):91-94. [doi: 10.1177/1403494810394715] [Medline: 21775362]

20. Familieindkomst. Statistics Denmark. URL: https://www.dst.dk/da/Statistik/dokumentation/Times/familieindkomst\# [accessed 2020-03-19]

21. The Danish Agency for Labour Market and Recruitment. Copenhagen; 2019. URL: https://star.dk/en [accessed 2021-01-12]

22. Mors O, Perto GP, Mortensen PB. The Danish psychiatric central research register. Scand J Public Health 2011 Jul;39(7 Suppl):54-57. [doi: 10.1177/1403494810395825] [Medline: 21775352]

23. Kildemoes HW, Sørensen HT, Hallas J. The Danish national prescription registry. Scand J Public Health 2011 Jul;39(7 Suppl):38-41. [doi: 10.1177/1403494810394717] [Medline: 21775349]

24. Arbejdskraftunders $\emptyset$ gelsen. Statistics Denmark. 2019. URL: https://www.dst.dk/da/Statistik/dokumentation/metode/ aku-arbejdskraftundersoegelsen [accessed 2020-03-19]

25. Hannerz H, Albertsen K, Burr H, Nielsen ML, Garde AH, Larsen AD, et al. Long working hours and stroke among employees in the general workforce of Denmark. Scand J Public Health 2018 May;46(3):368-374. [doi: 10.1177/1403494817748264] [Medline: 29251227]

26. Rønning M, Blix HS, Harbø BT, Strøm H. Different versions of the anatomical therapeutic chemical classification system and the defined daily dose--are drug utilisation data comparable? Eur J Clin Pharmacol 2000 Dec;56(9-10):723-727. [doi: 10.1007/s002280000200] [Medline: 11214783]

27. Brämer G. International statistical classification of diseases and related health problems. Tenth revision. World Health Stat Q 1988;41(1):32-36. [doi: 10.1007/978-0-387-79948-3 3055] [Medline: 3376487]

28. Parker G, Brotchie H. Gender differences in depression. Int Rev Psych 2010 Nov 03;22(5):429-436. [doi: 10.3109/09540261.2010.492391] [Medline: 21047157]

29. McLean CP, Asnaani A, Litz BT, Hofmann SG. Gender differences in anxiety disorders: prevalence, course of illness, comorbidity and burden of illness. J Psychiatr Res 2011 Aug;45(8):1027-1035 [FREE Full text] [doi: 10.1016/j.jpsychires.2011.03.006] [Medline: 21439576]

30. Wittchen H, Hoyer J. Generalized anxiety disorder: nature and course. J Clin Psychiatry 2001;62(Suppl 11):15-19. [Medline: 11414546]

31. Tjepkema M. Insomnia. Health Rep 2005 Nov;17(1):9-25. [Medline: 16335690]

32. Kessler RC, Birnbaum H, Bromet E, Hwang I, Sampson N, Shahly V. Age differences in major depression: results from the National Comorbidity Survey Replication (NCS-R). Psychol Med 2010 Feb;40(2):225-237 [FREE Full text] [doi: 10.1017/S0033291709990213] [Medline: 19531277]

33. Steinhausen H, Bisgaard C. Nationwide time trends in dispensed prescriptions of psychotropic medication for children and adolescents in Denmark. Acta Psychiatr Scand 2014 Mar;129(3):221-231. [doi: 10.1111/acps.12155] [Medline: 23738593] 
34. Andrade L, Caraveo-Anduaga JJ, Berglund P. Cross-national comparisons of the prevalences and correlates of mental disorders. WHO International Consortium in Psychiatric Epidemiology. Bull World Health Organ 2000;78(4):413-426 [FREE Full text] [Medline: 10885160]

35. Orpana H, Lemyre L, Gravel R. Income and psychological distress: the role of the social environment. Health Rep 2009 Mar;20(1):21-28 [FREE Full text] [Medline: 19388365]

36. Schlax J, Jünger C, Beutel ME, Münzel T, Pfeiffer N, Wild P, et al. Income and education predict elevated depressive symptoms in the general population: results from the Gutenberg health study. BMC Public Health 2019 Apr 24;19(1):430 [FREE Full text] [doi: 10.1186/s12889-019-6730-4] [Medline: 31014301]

37. Kosidou K, Dalman C, Lundberg M, Hallqvist J, Isacsson G, Magnusson C. Socioeconomic status and risk of psychological distress and depression in the Stockholm Public Health Cohort: a population-based study. J Affect Disord 2011 Nov;134(1-3):160-167. [doi: 10.1016/j.jad.2011.05.024] [Medline: 21665286]

38. Patel V, Burns JK, Dhingra M, Tarver L, Kohrt BA, Lund C. Income inequality and depression: a systematic review and meta-analysis of the association and a scoping review of mechanisms. World Psychiatry 2018 Feb;17(1):76-89 [FREE Full text] [doi: 10.1002/wps.20492] [Medline: 29352539]

39. O'Hara MW, McCabe JE. Postpartum depression: current status and future directions. Annu Rev Clin Psychol 2013 Mar 28;9(1):379-407. [doi: 10.1146/annurev-clinpsy-050212-185612] [Medline: 23394227]

40. Scarff J. Postpartum depression in men. Innov Clin Neurosci 2019 May 01;16(5-6):11-14 [FREE Full text] [Medline: $\underline{31440396]}$

41. Hannerz H, Tüchsen F, Holbæk Pedersen B, Dyreborg J, Rugulies R, Albertsen K. Work-relatedness of mood disorders in Denmark. Scand J Work Environ Health 2009 May 13;35(4):294-300. [doi: 10.5271/sjweh.1329] [Medline: 19436922]

42. Albertsen K, Hannerz H, Nielsen ML, Garde AH. Shift work and use of psychotropic medicine: a follow-up study with register linkage. Scand J Work Environ Health 2020 Jul 01;46(4):350-355 [FREE Full text] [doi: 10.5271/sjweh.3872] [Medline: 31830281]

43. Glossary: Equivalised disposable income. Eurostat. URL: https://ec.europa.eu/eurostat/statistics-explained/index.php/ Glossary:Equivalised_disposable_income [accessed 2020-03-04]

44. Statistics Denmark. Dansk Branchekode 1993, 2.udgave. Statistics Denmark. Copenhagen; 1996. URL: https://www.dst.dk/ Site/Dst/Udgivelser/GetPubFile.aspx?id=4829\&sid=dansk-branchekode-1993-hele-bogen [accessed 2021-01-12]

45. Dansk branchekode 2003 - DB03. Statistics Denmark. Copenhagen; 2002. URL: https://www.dst.dk/en/Statistik/ dokumentation/nomenklaturer/dansk-branchekode-db03 [accessed 2021-01-12]

46. Dansk branchekode 2007 - DB07. Statistics Denmark. Copenhagen; 2007. URL: https://www.dst.dk/en/Statistik/ dokumentation/nomenklaturer/dansk-branchekode-db07?id=d19945dc-6bdb-44db-ac13-e7433983c9ca [accessed 2021-01-12]

47. Pirani E, Salvini S. Is temporary employment damaging to health? A longitudinal study on Italian workers. Soc Sci Med 2015 Jan;124:121-131. [doi: 10.1016/j.socscimed.2014.11.033] [Medline: 25461869]

48. Wanberg CR, Kanfer R, Hamann DJ, Zhang Z. Age and reemployment success after job loss: an integrative model and meta-analysis. Psychological Bulletin 2016;142(4):400-426. [doi: 10.1037/bul0000019] [Medline: 26011790]

49. Virtanen M, Kivimäki M, Ferrie JE, Elovainio M, Honkonen T, Pentti J, et al. Temporary employment and antidepressant medication: a register linkage study. J Psych Res 2008 Feb;42(3):221-229. [doi: 10.1016/j.jpsychires.2006.12.005] [Medline: $\underline{17240396]}$

50. Hannerz H, Albertsen K, Nielsen ML, Garde AH. Prospective associations between working time arrangements and psychiatric treatment in Denmark: protocol for a cohort study. JMIR Res Protoc 2020 Jun 15;9(6):e18236. [doi: 10.2196/18236] [Medline: $\underline{32442158]}$

51. Cohen J. Statistical power analysis for the behavioral science. New Jersey: Lawrence Erlbaum Associates; 1988.

52. Rasmussen S, Nätti J, Larsen TP, Ilsøe A, Garde AH. Nonstandard employment in the Nordics - toward precarious work? Nordic J Working Life Stud 2019 Jun 01;9(S6) [FREE Full text] [doi: 10.18291/njwls.v9is6.114689]

53. Pasco JA, Williams LJ, Jacka FN, Ng F, Henry MJ, Nicholson GC, et al. Tobacco smoking as a risk factor for major depressive disorder: population-based study. Br J Psychiatry 2008 Oct;193(4):322-326. [doi: 10.1192/bjp.bp.107.046706] [Medline: 18827296$]$

54. Korhonen T, Broms U, Varjonen J, Romanov K, Koskenvuo M, Kinnunen T, et al. Smoking behaviour as a predictor of depression among Finnish men and women: a prospective cohort study of adult twins. Psychol Med 2007 May;37(5):705-715. [doi: 10.1017/S0033291706009639] [Medline: 17181913]

55. Luppino FS, de Wit L, Bouvy PF, Stijnen T, Cuijpers P, Penninx BW, et al. Overweight, obesity, and depression: a systematic review and meta-analysis of longitudinal studies. Arch Gen Psychiatry 2010 Mar;67(3):220-229. [doi:

10.1001/archgenpsychiatry.2010.2] [Medline: 20194822]

56. Feveile H, Olsen O, Burr H, Bach E. Danish work environment cohort study 2005: from idea to sampling design. Statis Transition 2007;8:441-458 [FREE Full text]

57. Foo SQ, Tam WW, Ho CS, Tran BX, Nguyen LH, McIntyre RS, et al. Prevalence of depression among migrants: a systematic review and meta-analysis. Int J Environ Res Public Health 2018 Dec 12;15(9) [FREE Full text] [doi: 10.3390/ijerph15091986] [Medline: 30213071] 
58. Akhavan S, Bildt C, Wamala S. Work-related health factors for female immigrants in Sweden. Work 2007;28(2):135-143. [Medline: 17312345$]$

59. Solé M, Diaz-Serrano L, Rodríguez M. Disparities in work, risk and health between immigrants and native-born Spaniards. Social Science \& Medicine 2013 Jan;76:179-187. [doi: 10.1016/j.socscimed.2012.10.022] [Medline: 23164972]

60. Smith P, Mustard C. Comparing the risk of work-related injuries between immigrants to Canada and Canadian-born labour market participants. Occup Environ Med 2009 Jun;66(6):361-367 [FREE Full text] [doi: 10.1136/oem.2007.038646] [Medline: 18614627]

61. Christensen A, Ekholm O, Glümer C, Andreasen A, Hvidberg M, Kristensen P, et al. The Danish National Health Survey 2010. Study design and respondent characteristics. Scand J Public Health 2012 Jun;40(4):391-397 [FREE Full text] [doi: 10.1177/1403494812451412] [Medline: 22786925]

62. Christensen AI, Ekholm O, Glümer C, Juel K. Effect of survey mode on response patterns: comparison of face-to-face and self-administered modes in health surveys. Eur J Public Health 2014 Apr;24(2):327-332. [doi: 10.1093/eurpub/ckt067] [Medline: 23766339]

63. Bredgaard T, Madsen PK. Farewell flexicurity? Danish flexicurity and the crisis. Transfer (Bruss) 2018 Apr 19;24(4):375-386. [doi: $10.1177 / 1024258918768613]$

\author{
Abbreviations \\ ATC: Anatomical Therapeutic Chemical Classification System \\ CPR: Central Person Register \\ DLFS: Danish Labor Force Survey \\ DREAM: Danish Register for Evaluation of Marginalization \\ ECM: Employment Classification Module \\ EU: European Union \\ ICD-10: International Statistical Classification of Diseases and Related Health Problems, 10th Revision \\ OECD: Organization for Economic Co-operation and Development \\ RR: rate ratio
}

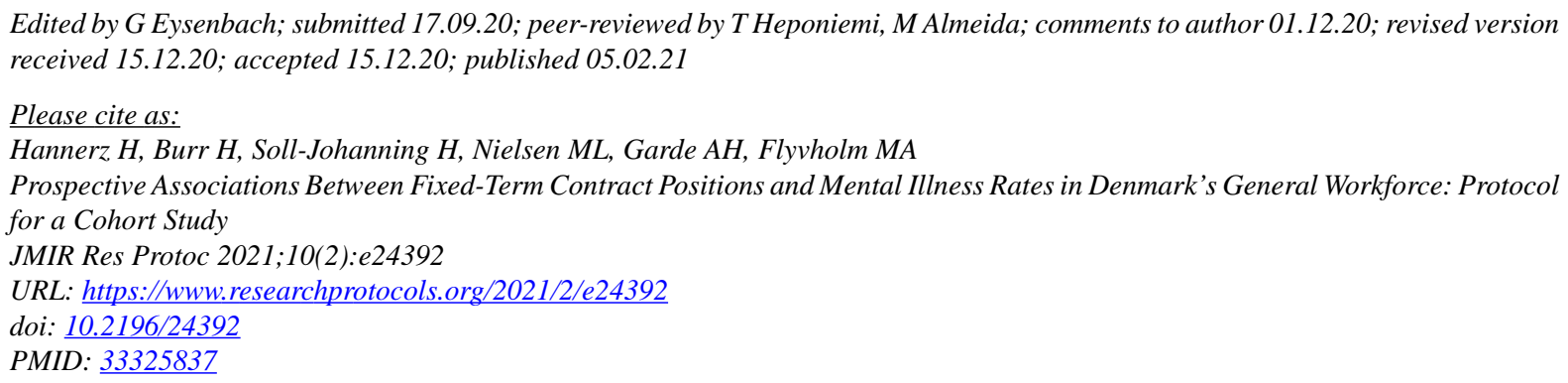

(CHarald Hannerz, Hermann Burr, Helle Soll-Johanning, Martin Lindhardt Nielsen, Anne Helene Garde, Mari-Ann Flyvholm. Originally published in JMIR Research Protocols (http://www.researchprotocols.org), 05.02.2021. This is an open-access article distributed under the terms of the Creative Commons Attribution License (https://creativecommons.org/licenses/by/4.0/), which permits unrestricted use, distribution, and reproduction in any medium, provided the original work, first published in JMIR Research Protocols, is properly cited. The complete bibliographic information, a link to the original publication on http://www.researchprotocols.org, as well as this copyright and license information must be included. 